\title{
APLIKASI COMMODITY SYSTEM ASSESSMENT METHOD DALAM DISTRIBUSI JAGUNG (Zea mays) DARI PETANI DI KECAMATAN KLUNGKUNG KE PENGECER
}

\author{
Pande Made Kerta Indra Yoga ${ }^{1}$, Bambang Admadi Harsojuwono ${ }^{2}$, I.G.A Lani Triani ${ }^{3}$ \\ ${ }^{1}$ Mahasiswa Jurusan Teknologi Industri Pertanian, Fakultas Teknologi Pertanian, UNUD \\ ${ }^{2}$ Dosen Jurusan Teknologi Industri Pertanian, Fakultas Teknologi Pertanian, UNUD \\ E-mail: pandeyoga94@yahoo.com ${ }^{1}$ \\ Email koresponden: bambang.admadi@unud.ac.id ${ }^{2}$
}

\begin{abstract}
ABSTRAK
The purpose of this research was to determine the number of distribution corn (Zea mays), the type of distribution and postharvest handling of corn, and the impact of postharvest losses and the value of the damage of farmers to retailers Klungkung district. The method used in this research is survey method with the application of the Commodity Systems Assessment Method in the form of questionnaires distributed to farmers, collectors, wholesalers, suppliers and retailers of corn. In the distribution of corn, there are four lines, namely, lanes I farmers retailers, lane II farmers collectors retailers, lane III farmers collectors wholesalers retailers, lines IV farmers collectors wholesalers suppliers supermarkets. Post-harvest handling at the farm level include harvesting, sorting and cleaning, packaging and transportation. Post-harvest handling at the level of collectors, and wholesalers include weighing, sorting, and transporting, postharvest handling at the retail level covering inspection, packaging, and display, postharvest handling at the level of suppliers includes weighing, sorting, packaging and transportation, postharvest handling level includes supermarkets weighing, inspection, and display. Impact on corn postharvest losses at the farm level, namely the harvest reached 7\% (significant), at the level of the collectors in the transport process is reached $2.68 \%$ (not significant), at the level of big traders when transporting reached $3.8 \%$ (not significant), at the retail level in sorting reached $2.38 \%$ (not significant), in the sorting supplier level of $11.8 \%$ (significant).
\end{abstract}

Keyword : Distribution line, postharvest, corn, CSAM.

\section{PENDAHULUAN}

Jagung (Zea mays) merupakan sumber karbohidrat yang merupakan alternatif pangan (Nurwahidah et al., 2015). Pramono (2015) menyatakan jagung merupakan komoditas tanaman pangan yang menjadi prioritas setelah padi. Pemerintah mencanangkan upaya peningkatan produksi jagung tahun 2014 dengan target yang harus dicapai tahun 2015 yaitu 20,31 juta ton dengan pertumbuhan 1.114.000,31 juta ton melalui upaya khusus peningkatan produksi pajale (padi jagung kedelai).

Terjadi peningkatan kebutuhan jagung setiap tahun yaitu tahun 2015 kebutuhan jagung manis sebesar 30.603 ton dan di tahun 2016 sebesar 31.425 ton hal inidiakibatkan oleh 
meningkatnya jumlah penduduk Provinsi Bali tahun 20154.152.800 jiwa dan tahun 2016 4.200.100 jiwa (Anon, 2016). Permasalahan tersebut memicu para petani untuk meningkatkan penanaman jagung hususnya di Kecamatan Klungkung. Penanaman jagung ditingkatkan karena mudah dalam penanaman, perawatan, dan harga jual yang setabil di pasaran, sehingga masyarakat sangat menyukai jagung manis. Saat ini pemerintah sangat peduli terhadap petani jagung hususnya upaya meningkatkan produksinya, pemerintah daerah memberikan bantuan alat bajak sawah dan pupuk, supaya hasil produksi terus mengalami peningkatan.

Di Provensi Bali ada 8 Kabupaten dan 1 Kotamadia dan terdapat beberapa Kabupaten yang menjadi penghasil jagung manis diantaranya Kabupaten Jembrana, Tabanan, Gianyar, Buleleng, dan Klungkung. Dari kelima Kabupaten penghasil jagung manis, Kabupaten Klungkung merupakan penghasil terbesar dengan jumlah produksi pada tahun 2016 sebesar 1.450 ton dan luas produksi 15 Ha. Di Kabupaten Klungkung tersebut, Kecamatan Klungkung adalah penghasil jagung manis terbesar, dengan dua Desa yang menjadi penghasil jagung manis yaitu Desa Gelgel dan Desa Jumpai (Anon., 2014b).

Sentra jagung manis yang dihasilkan oleh petani di Kecamatan Klungkung mengalami beberapa jalur distribusi sebelum mencapai ke tangan konsumen seperti pengepul, pedagang besar, dan pengecer. Mutu dari jagung manis tergantung pada panjang atau pendeknya jalur distribusi yang dilalui oleh jagung manis tersebut dari petani sebagai produsen sampai kepada konsumen. Disamping itu penanganan pascapanen seperti sortasi, grading, pencucian, pengemasan dan penyimpanan juga mempengaruhi kondisi dan mutu jagung selama pendistribusian. Dengan semakin panjangnya jalur distribusi, maka semakin banyak variasi penanganan yang dialami sehingga makin besar pula tingkat kerusakannya (Harsojuwono, 2008).

Penanganan jagung yang benar dapat menghasilkan komoditi yang siap dipasarkan dengan mutu yang baik. Jagung yang dihasilkan oleh petani mengalami beberapa jalur distribusi sebelum sampai ke tangan konsumen. Jalur distribusi yang berbeda akan menyebabkan penanganan yang berbeda sehingga kerusakan pada tiap jalur distribusi juga berbeda. Jalur distribusi dan cara pengangkutan juga sangat berpengaruh terhadap kualitas mutu produk .Dengan semakin panjangnya jalur distribusi, maka semakin banyak variasi penanganan yang dialami sehingga makin besar pula tingkat kerusakannya (Harsojuwono, 2008). CSAM atau sistem penilaian komiditi adalah suatu metode penilaian sistem komoditi hortikultura yang bertujuan untuk mengidentifikasi dan mendeskripsikan masalah serta mengidentifikasi dan memformulasikan pemecahan masalah yang tepat dari faktor-faktor dan cara-cara penanganan yang mempengaruhi mutu, kehilangan, kerusakan, kerugian secara ekonomi dalam rantai distribusi (Harsojuwono, 2008). Penerapan CSAM dan dengan diperkuatnya rantai distribusi maka akan diperoleh produkproduk hortikultura berkualitas dan bermutu yang mampu bersaing di pasaran. Untuk menjaga mutu jagung maka 
diperlukan penanganan yang benar sehingga dihasilkan komoditi yang siap dipasarkan dengan mutu seperti keinginan konsumen. Perlu dilakukan penelitian pascapanen jagung untuk mengetahui penanganan menggunakan metode Commodity System Assessment Method. Melalui metode CSAM diharapkan bisa mengevaluasi penanganan pascapanen jagung dari petani ke konsumen. Dengan metode tersebut, penanganan pascapanen jagung sejak awal sampai pemasarannya bisa dipantau.

\section{METODE PENELITIAN}

Penelitian dilaksanakan di Kecamatan Klungkung, Kabupaten Klungkung dan Kota Denpasar. Metode penelitian yang digunakan adalah metode snow ball sample, dengan aplikasi CSAM (Commodity System Assessment Method) dan menggunakan alat survei berupa kuisioner yang disebarkan pada petani, pengepul, pedagang besar, dan pengecer jagung di Kecamatan Klungkung. Populasi yang diamati adalah petani, pengepul, pedagang besar, dan pengecer yang terlibat dalam distribusi jagung dari petani di Kecamatan Klungkung untuk di distribusikan sampai ke pengecer. Berdasarkan syarat pengambilan sampel, diperlukan data minimal 30\% (Singarimbun dan Effendi, 1989) sehingga diperlukan sampel petani 30\% dari seluruh jumlah petani jagung di Kecamatan Klungkung. Jika jumlah seluruh petani kurang dari 30 unit, maka seluruh anggota populasi menjadi sampel. Jumlah petani yang ada di Desa Gelgel 10 orang dan di Desa Jumpai 8 orang sehingga seluruh jumlah petani dipakai karena kurang dari 30 orang dapat dilihat pada Tabel 1 :

Tabel 1. Jumlah petani, pengecer, pengepul, pedagang besar, dan suplier

\begin{tabular}{lll}
\hline No & Data hasil survei & Jumlah \\
\hline 1 & Petani & 18 orang $*$ \\
2 & Pengepul & 2 orang \\
3 & Pedagang Besar & 1 orang \\
4 & suplier & 2 orang \\
5 & pengecer & 11 Orang \\
\hline
\end{tabular}

Keterangan :

*Untuk 18 petani didapat dari 2 desa yaitu 10 orang dari desa Gelgel dan 8 orang dari desa Jumpai . Luas lahan dari masing-masing petani adalah 4-35 are.

Variabel yang diamati dari distribusi jagung adalah jalur distribusi, sistem penanganan pasca panen. Sampel penelitian adalah petani jagung dari petani yang ada di Kecamatan Klungkung, suplier dan pengecer. Tahapan pelaksanaan penelitian dapat dilihat pada Gambar 1. 


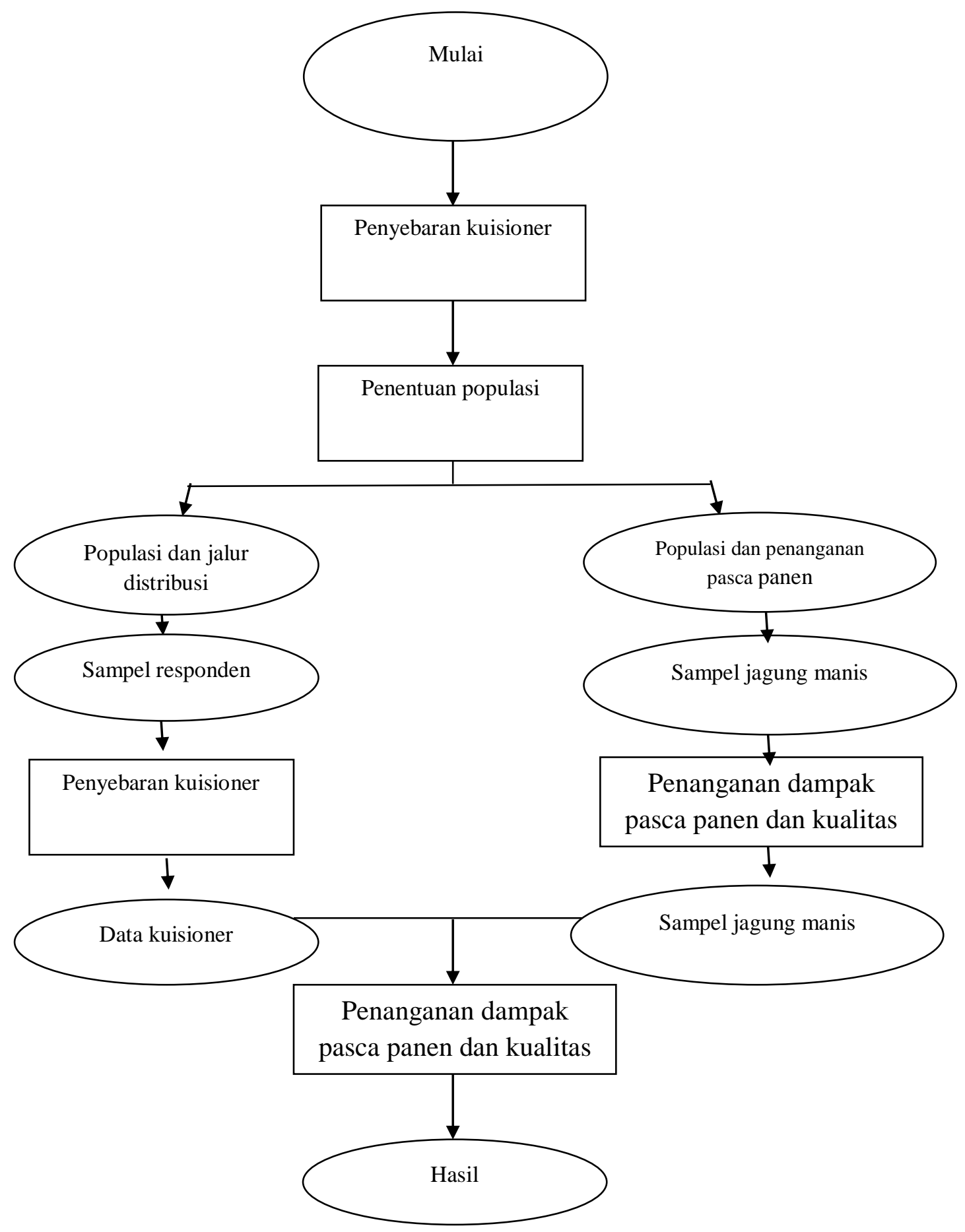

Gambar 1. Diagram alir pelaksanaan penelitian. 


\section{HASIL DAN PEMBAHASAN}

\section{Jalur distribusi jagung dari petani di Kecamatan Klungkung sampai ke pengecer.}

\section{Jalur I. Petani $\rightarrow$ Pengecer}

Pada jalur ini petani di Kecamatan Klungkung menjual jagung langsung ke pengecer di pasar Klungkung. Petani dan pengecer pasar pada jalur ini berasal dari wilayah desa yang berbeda. Jumlah petani pada jalur pertama 12 orang.

\section{Jalur II. Petani $\rightarrow$ Pengepul $\rightarrow$ Pengecer}

Pada jalur ini petani di Kecamatan Klungkung menjual jagung kepada pengepul dengan cara pengepul mengambil jagung langsung di lahan petani. Kemudian pengepul menjual jagunkepengecerdpasar tradisonal. Jalur ini menunjukkan bahwa pengepul sebagai pemegang peranan penting untuk memastikan para pedagang pasar tradisional mendapatkan pasokan jagung. Hal ini sesuai dengan pendapat Widiastuti dan Hasanudin (2013) setiap lembaga pemasaran mempunyai peranan penting dalam kegiatan pemasaran yaitu petani berperan sebagai penghasil jagung, pengepul sebagai pedagang perantara petani dengan pengecer, sedangkan pengecer berperan sebagai pedagang yang berhubungan langsung dengan konsumen. Jumlah petani yang ada pada jalur kedua sebanyak 6 orang.

\section{Jalur III. Petani $\rightarrow$ Pengepul --- Pedagang besar --- Pengecer}

Pada jalur III petani di Kecamatan Klungkung menjual jagung pada pengepul dengan cara pengepul mengambil langsung ke lahan petani, kemudian pengepul menjual jagung ke Pedagang besar jagung, selanjutnya jagung di beli oleh pengecer dengan cara pengecer mendatangi pedagang besar. Hal ini sesuai dengan pendapat Rum (2011) yang menyatakan bahawa pengecer adalah rantai pemasaran terakhir yang langsung berhadapan dengan konsumen. Debgan jumlah petani pada jalur ketiga 4 orang.

\section{Jalur IV. Petani ---- Pengepul ---- Pedagang besar ---- Suplier swalayan ---- swalayan.}

Pada jalur IV petani di Kecamatan Klungkung menjual jagung pada pengepul dengan cara pengepul mengambil langsung ke lahan petani, kemudian pengepul menjual jagung ke Pedagang besar jagung, selanjutnya jagung di beli oleh suplier pasar swalayan dengan cara pedagang besar mengirim ke suplier swalayan, kemudian suplier swalayan menjual jagung ke swalayan. Dengan jumlah petani 5 orang.

Penanganan pascapanen jagung pada jalur distribusi dari petani di Kecamatan Klungkung ke pengecer. Penanganan pascapanen di tingkat petani.

a. Pemanenan : Dilakukan setelah jagung berumur 90 hari. Dengan memotong bagian pangkal tongkol atau dengan menggunakan sabit.

b. Sortasi : memisahkan antara jagung yang baik dengan yang kurang baik, menghilangkan pericarp bagian luar yang sudah menguning, terkena penyakit atau berlubang.

c. Pengemasan : Menggunakan karung, bertujuan untuk mempermudah pengangkutan atau transportasi.

\section{Penanganan pascapanen di tingkat pengepul.}

a. Penimbangan : Dilakukan dengan menggunakan timbangan manual.

b. Pengangkutan : Diangkut menggunakan mobil bak terbuka menuju ke pedagang besar atau pengecer. 


\section{Penanganan pascapanen di tingkat pedagang besar.}

a. Penimbangan : Dilakukan dengan menggunakan timbangan manual.

b. Pengangkutan : menggunakan mobil bak terbuka menuju ke pengecer.

\section{Penanganan pascapanen di tingkat suplier swalayan.}

a. Penimbangan : Dilakukan dengan menggunakan timbangan manual.

b. Sortasi : Dilakukan dengan cara mengeluarkan jagung dari keranjang dan kemudian dibedakan menurut ukuran serta dilakukan penghilangan pericarp yang rusak.

c. Pengemasan : Dilakukan dengan cara wrapping dengan menggunakan film plastik.

d. Pengangkutan : Diangkut menggunakan mobil bak tertutup menuju ke swalayan.

\section{Identifikasi pelaku penanganan pascapanen di tingkat petani}

Pemanenan jagung dilakukan setelah jagung berumur 90 hari. Pemanenan dilakukan dengan memotong bagian pangkal batang dengan menggunakan sabit. Sortasi bertujuan untuk memisahkan antara jagung yang baik dengan yang kurang baik dengan cara menghilangkan pericarp yang rusak terkena penyakit atau berlubang. Setelah proses sortasi selesai, kemudian dilanjutkan dengan proses pengemasan jagung. Pengemasan dilakukan dengan menggunakan karung dan plastik. Pengemasan bertujuan untuk mempermudah pengangkutan atau transportasi.

\section{Identifikasi pelaku penanganan pascapanen di tingkat pengepul.}

Penimbangan dilakukan untuk mengetahui berat jagung secara keseluruhan. Penimbangan dilakukan dengan menggunakan timbangan manual. Jagung dalam karung yang sudah di timbang diangkut menggunakan mobil bak terbuka menuju ke pedagang besar atau pengecer.

\section{Identifikasi pelaku penanganan pascapanen di tingkat pedagang besar.}

Sortasi dilakukan dengan cara mengeluarkan jagung dari karung dan kemudian dibedakan menurut ukuran serta dilakukan penghilangan pericarp yang rusak. Jagung dalam karung dan plastik yang sudah di timbang diangkut menggunakan mobil bak terbuka menuju ke pengecer

\section{Identifikasi pelaku penanganan pascapanen di tingkat pengecer.}

Sortasi yang bertujuan untuk mengetahui ada tidaknya kerusakan pada jagung yang diterima dari pengepul. Tahapan sortasi ini dilakukan dengan cara menghilangkan pericarp yang layu dan rusak. Kemudian dilakukan pemajangan jagung dengan cara di letakkan pada rak-rak dengan baik tanpa menggunakan kemasan lagi.

\section{Identifikasi pelaku penanganan pascapanen di tingkat suplier swalayan.}

Di tingkat ini sortasi dilakukan dengan cara mengeluarkan jagung dari karung dan kemudian dibedakan menurut ukuran serta dilakukan penghilangan pericarp yang rusak. Pengemasan dilakukan dengan cara wrapping dengan menggunakan film plastik. Jagung dalam keranjang plastik yang sudah dikemas diangkut menggunakan mobil bak tertutup menuju ke swalayan. 
Tabel 2. Diagram alir sistem pascapanen jagung dari petani ke pengecer di Kecamatan Klungkung.

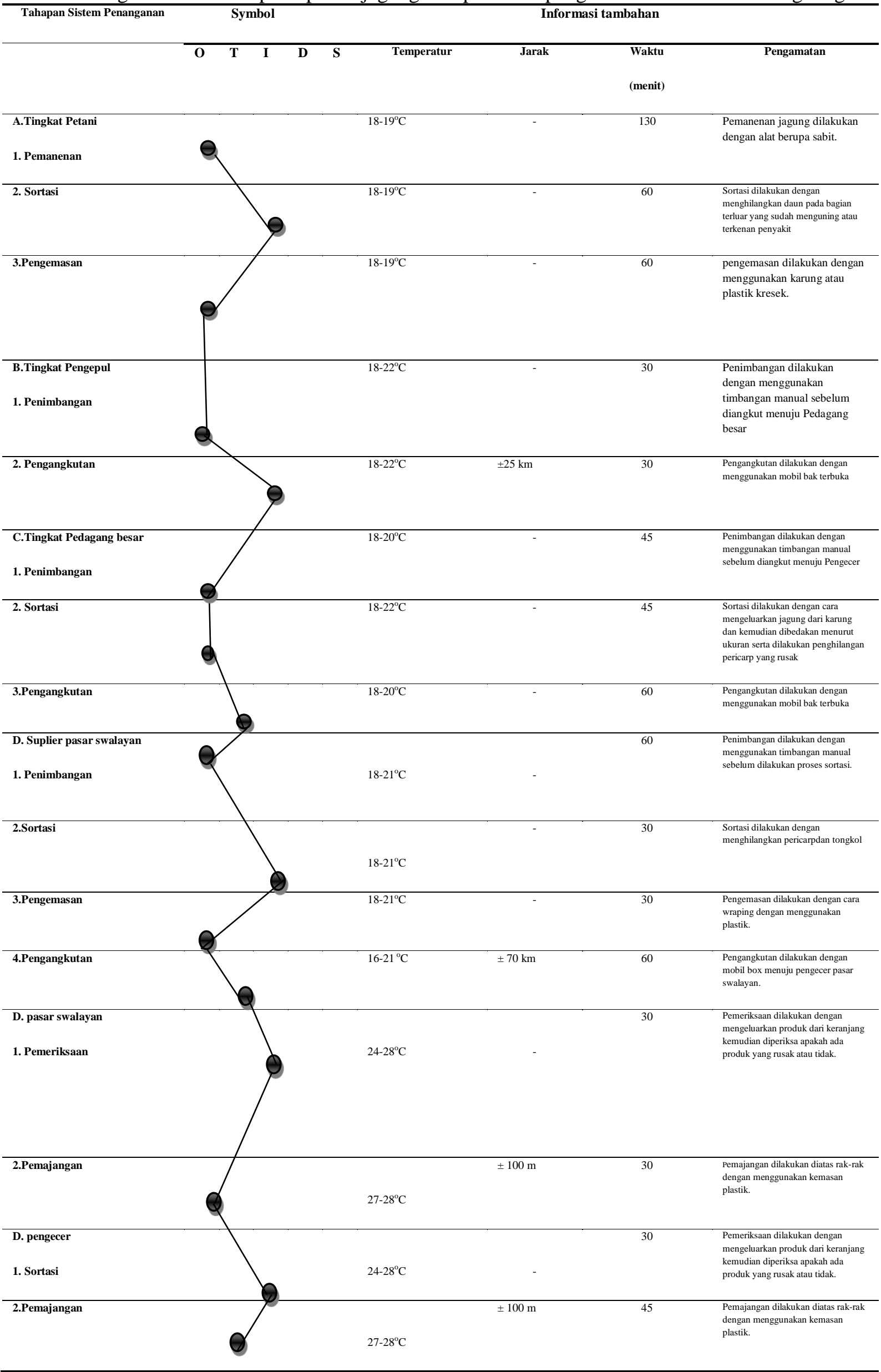




\section{Identifikasi pelaku penanganan pascapanen di tingkat suplier swalayan.}

Penimbangan dilakukan dengan menggunakan timbangan digital. Jagung dalam keranjang plastik dikeluarkan untuk dipilih dan diperiksa, apabila ada daun yang rusak atau berlubang. Pemajangan dilakukan dengan menata secara rapi jagung diatas rak-rak dengan kemasan plastic

\section{Dampak penanganan selama distribusi terhadap kehilangan pascapanen jagung dari petani ke pengecer di Kecamatan Klungkung.}

Pada tingkat petani sekali panen mendapatkan jagung $1197 \mathrm{Kg}$ dengan kehilangan susut bobot saat sortasi sebesar $87 \mathrm{Kg}$, ini menunjukkan hasil panen, kehilangan saat sortasi, dan hasil panen bersih dengan presentase hasil panen bersih jagung mencapai 93\% dan kehilangan saat sortasi 7,57 \%. Kehilangan saat sortasi jagung terjadi karena mengalami kerusakan seperti pericarp yang sudah kuning dan berlubang.

Pada tingkat pengepul jumlah jagung yang dibeli sebanyak $967 \mathrm{Kg}$ dengan susut bobot akibat sortasi $26 \mathrm{Kg}$. Menunjukkan hasil pembelian, kehilangan susut bobot, dan penjualan. Rata-rata penjualan produk jagung di tingkat pengepul mencapai 97,32\% dan tingkat kehilangan susut bobot mencapai 2, 68\%. Hal ini disebabkan oleh perbedaan suhu dalam proses pendistribusian saat jagung berada di petani dan pada saat berada di pengepul sehingga menyebabkan terjadinya laju respirasi pada jagung yang berakibat pada penurunan kadar air dan penurunan berat pada jagung. Laju respirasi atau kehilangan air dipengaruhi oleh faktor-faktor internal (karakteristik morfologi dan anatomi, luas permukaan dan volume, pelukaan pada permukaan dan stadia kematangan), dan faktor eksternal atau faktor-faktor lingkungan (suhu, kelembaban, aliran udara dan tekanan atmosfer). Semakin tinggi laju respirasi maka semakin cepat pula perombakanperombakan tersebut yang mengarah pada kemunduran dari produk tersebut (Utama,2011).

Pada tingkat pedagang besar jumlah jagung yang dibeli total $651 \mathrm{Kg}$ dengan susut bobot akibat sortasi $25 \mathrm{Kg}$. Menunjukkan hasil pembelian jagung dari pengepul, kehilangan susut bobot, dan penjualan dengan presentase rata-rata penjualan produk di tingkat pedagang besar mencapai 96,2\% dan kehilangan susut bobot adalah 3,8\%. Penyebab kerusakan jagung disebabkan adanya getaran, gesekan dan benturanbenturan mekanis selama proses distribusi dari pengepul menuju pedagang besar. Menurut Susiwi (2009), kerusakan mekanis disebabkan oleh terjadinya benturan antar bahan selama pengangkutan (tertindih atau tertekan) maupun terjatuh, sehingga mengalami cacat berupa memar.

Pada tingkat supplier swalayan membeli jagung total $380 \mathrm{Kg}$ dengan susut bobot akibat sortasi 45 Kg. menunjukkan hasil pembelian jagung, kehilangan susut bobot, dan penjualan. Presentase rata-rata pejualan produk di tingkat suplier mencapai $88,15 \%$ dan kehilangan susut bobot mencapai 11,8\%. Kehilangan susut bobot terjadi saat sortasi. Kerusakan yang terjadi separti pelayuan, berubahan warna, dan memar-memar. Kerusakan fisik seperti memar dan luka pada jagung dapat mengakibatkan kerusakan yang lebih serius, yaitu penurunan kualitas jagung secara kimiawi maupun mikrobiologis, jagung yang mengalami luka fisik, selain tampilannya menjadi kurang baik, juga akan memicu terjadinya pembusukan (Qanitah, 2011). 
Pada tingkat pengecer membeli jagung total $714 \mathrm{Kg}$ dengan susut bobot $17 \mathrm{Kg}$. Menunjukkan hasil pembelian jagung, kehilangan susut bobot, dan penjualan. Presentase rata-rata pejualan produk di tingkat pengecer mencapai $91,45 \%$ dan kehilangan susut bobot mencapai $8,55 \%$. Kehilangan susut bobot terjadi saat sortasi. Kerusakan yang terjadi seperti pelayuan, berubahan warna, dan memar-memar. Kerusakan fisik seperti memar dan luka pada jagung dapat mengakibatkan kerusakan yang lebih serius, yaitu penurunan kualitas jagung secara kimiawi maupun mikrobiologis, jagung yang mengalami luka fisik, selain tampilannya menjadi kurang baik, juga akan memicu terjadinya pembusukan (Qanitah, 2011).

Dampak penanganan pascapanen jagung berdasarkan tingkat kehilangan pascapanen. Semakin tinggi susut bobot, maka produk tersebut semakin berkurang tingkat kesegarannya. Presentase dampak penanganan terhadap kehilangna pascapanen dapat dilihat pada Tabel 3

Tabel 3. Presentase dampak penanganan terhadap kehilangna pascapanen.

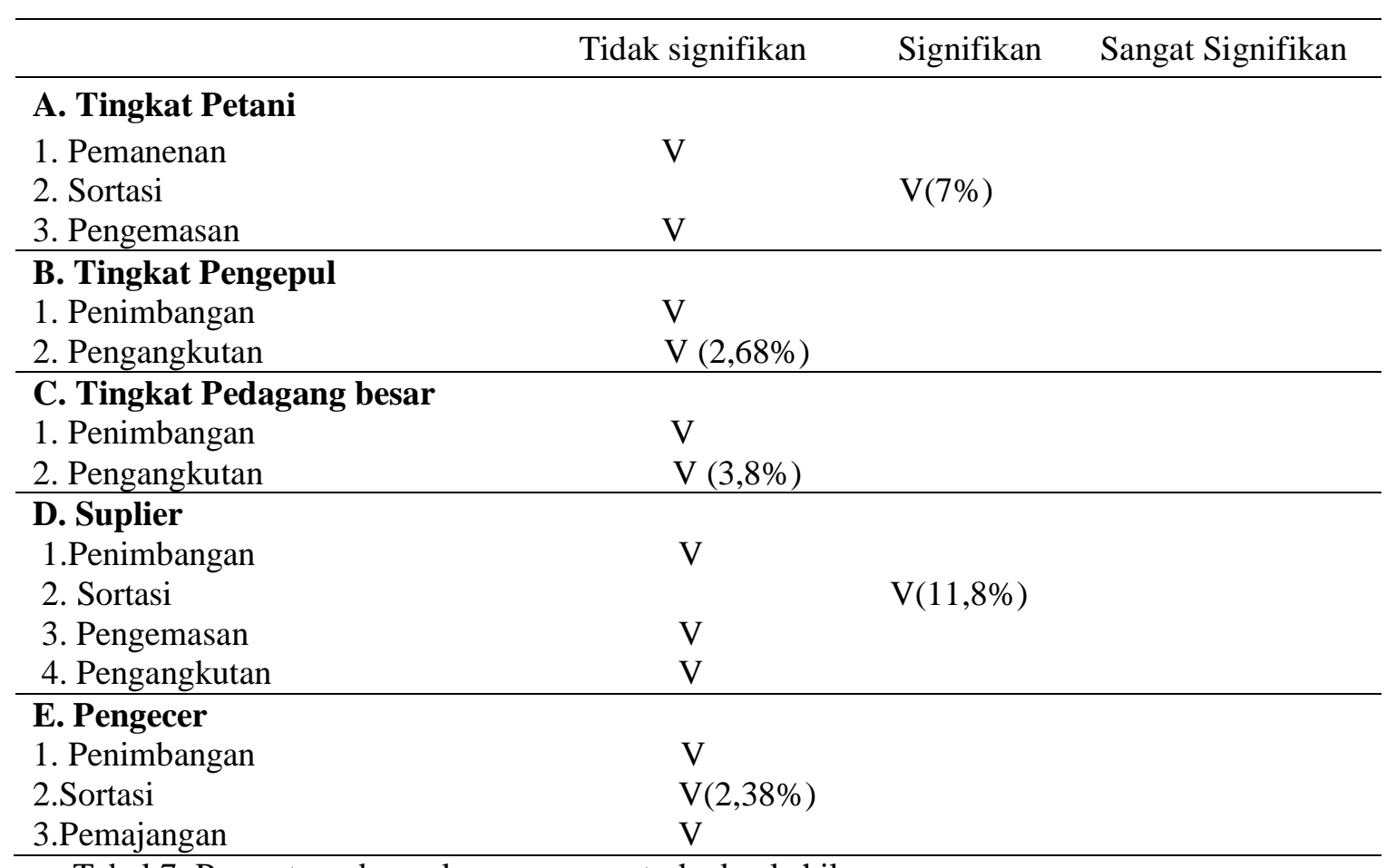

Tabel 7. Presentase dampak penanganan terhadap kehilangan pascapanen.

Keterangan : Tidak signifikan: $<5 \%$

$$
\begin{array}{ll}
\text { Signifikan } & : 5-30 \% \\
\text { Sangat signifikan } & :>30 \%(\text { La Gra, 1999) } \\
\text { V } & : \text { Posisi signifikansi }
\end{array}
$$




\section{KESIMPULAN DAN SARAN}

\section{Kesimpulan}

1) Terdapat 4 jalur distribusi jagung dari petani ke pengecer di Kecamatan Klungkung, yaitu jalur I (Petani, Pengecer), jalur II (Petani, Pengepul, Pengecer), jalur III (Petani, Pengepul, Pedagang besar, Pengecer), IV (Petani, Pengepul, Pedagang besar, Suplier, Swalayan).

2) Penanganan pascapanen di tingkat petani meliputi pemanenan, sortasi, pengemasan, dan pengangkutan. Penanganan pascapanen di tingkat pengepul dan pedagang besar meliputi penimbangan dan pengangkutan, penanganan pascapanen di tingkat suplier meliputi penimbangan, sortasi, pengemasan dan pengangkutan, penanganan pascapanen di tingkat pengecer meliputi sortasi, dan pemajangan, penanganan pascapanen di tingkat swalayan meliputi penimbangan, pemeriksaan, dan pemajangan.

3) Dampak penanganan selama distribusi terhadap kehilangan pascapanen jagung di tingkat petani yaitu pada sortasi signifikan mencapai 7,57 \%. Pada tingkat pengepul yaitu pada pengangkutan adalah tidak signifikan 2,68\%. Pada pedagang besar yaitu pada pengangkutan adalah tidak signifikan 3,8\%. Dampak kehilangan pada suplier yaitu pada sortasi adalah signifikan 11,8\% Dampak kehilangan pada pengecer yaitu pada pemajangan adalah tidak signifikan 2,38\%. Perbandingan jagung pada jalur I sesuai dengan color chart jagung no 3 yaitu jagung 2 hari setelah panen, perbandingan jagung pada jalur II sesuai dengan color chart jagung no 6 yaitu jagung 5 hari setelah panen, perbandingan jagung pada jalur III sesuai dengan color chart jagung no 8 yaitu jagung 7 hari setelah panen, perbandingan jagung pada jalur IV sesuai dengan color chart jagung no 3 yaitu jagung 2 hari setelah panen.

\section{Saran}

1) Perlu dilakukan perbaikan-perbaikan penanganan pascapanen pada tiap tingkat agar menghasilkan produk hortikultura yang baik.

2) Disarankan agar konsumen lebih memilih produk yang masih segar agar kandungan gizi yang terkandung didalamnya tidak berkurang.

\section{DAFTAR PUSTAKA}

Anonimus. 2014a. Klungkung dalam Angka 2014. Bappeda Kabupaten Klungkung. BPS Kabupaten Klungkung. Klungkung.

Anonimus. 2015a. Balai Penyuluhan Pertanian Perikanan dan Kehutanan Kecamatan Klungkung, Kabupaten Klungkug.

Anonimous. 2016a. Penduduk Provinsi Bali (Tabel \& Grafik Dinamis). BPS Provinsi Bali.

Budiastra, I.G, I.G.A.L. Triani., dan A. Hartiati. 2017. Aplikasi Commodity System Assessment Method (CSAM) Dalam Distribusi Kubis (Brassica Oleraceae Var. Capitata) Dari Petani di Kecamatan Petang ke Pengecer Jurnal Rekayasa dan Manajemen Agroindustri 5.1 (2017): 12-20.

Harsojuwono, B., A. 2008. Pentingnya Penerapan Commodity System Assessment Method (CSAM) Pada Penanganan Dan Distribusi Produk Hortikultura. Orasi Ilmiah Guru Besar. UNUD, Badung. 
La Graa, 1999. A Commodity System Assessment Methodology for Problem and project Identification. Postharvest Institute for Parishable, College of Agriculture. University of Idaho, Moscow.

Nurwahidah, S., H.D. Dwidjono dan R.W. Lestari. 2015. Technical efficiency of corn in Sumbawa Regency. International Journal of Computer Applications 126(7): 36-40.

Pramono, J. 2015. Dukungan Balitbangtan pada Program UPSUS Peningkatan Produksi Padi, Jagung dan

Qanytah dan I. Ambarsari, 2011. Efisiensi Penggunaan Kemasan Kardus Distribusi Mangga Arumanis. Jurnal Pengkajian dan Pengembangan Teknologi Pertanian. Volume 30 Nomor 1. Balai Besar P2TP Bogor. Bogor.

Singarimbun, M. dan S. Effendi. 1989. Metode Penelitian Survai. P3ES. Jakarta.

Susiwi, S. 2009. Kerusakan Pangan. Skripsi tidak dipublikasikan. Jurusan Pendidikan Kimia. Universitas Pendidikan Indonesia, Jakarta.

Suwarjana, I.P.E, I.G.A.L. Triani., dan B.A. Harsojuwono. 2015. Aplikasi Commodity System Assessment Method (CSAM) Dalam Distribusi Sawi Pakcoy (Brassica Rapa L) Dari Petani di Kecamatan Baturiti ke Pengecer Jurnal Rekayasa dan Manajemen Agroindustri 3.4 (2015): 140-148. 